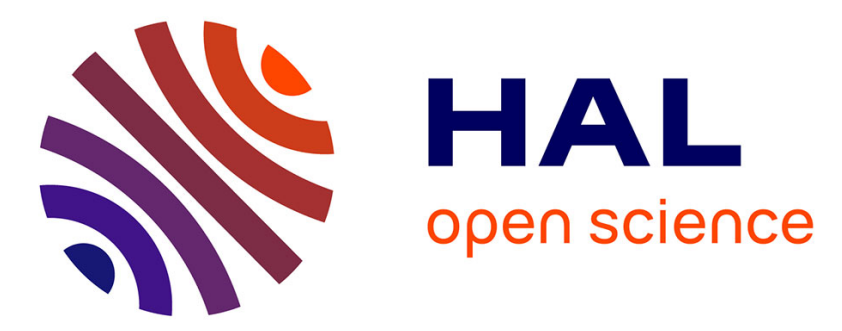

\title{
Tree species diversity and abundance as indicators of understory diversity in French mountain forests: Variations of the relationship in geographical and ecological space \\ C. Zilliox, Frédéric Gosselin
}

\section{To cite this version:}

C. Zilliox, Frédéric Gosselin. Tree species diversity and abundance as indicators of understory diversity in French mountain forests: Variations of the relationship in geographical and ecological space. Forest Ecology and Management, 2014, 321, pp.105-116. 10.1016/j.foreco.2013.07.049 . hal-01094414

\author{
HAL Id: hal-01094414 \\ https://hal.science/hal-01094414
}

Submitted on 12 Dec 2014

HAL is a multi-disciplinary open access archive for the deposit and dissemination of scientific research documents, whether they are published or not. The documents may come from teaching and research institutions in France or abroad, or from public or private research centers.
L'archive ouverte pluridisciplinaire HAL, est destinée au dépôt et à la diffusion de documents scientifiques de niveau recherche, publiés ou non, émanant des établissements d'enseignement et de recherche français ou étrangers, des laboratoires publics ou privés. 
1 Tree species diversity and abundance as indicators of understory

2 diversity in French mountain forests: variations of the relationship

3 in geographical and ecological space

4

* : corresponding author ; e-mail: frederic.gosselin@irstea.fr; phone: +33238950358

14 Published in Forest Ecology and Management (vol. 321, pages 105-116, doi: 10.1016/j.foreco.2013.07.049) 1 : IRSTEA, UR EFNO, Domaine des Barres, F-45290 Nogent-sur-Vernisson, France 2 : AgroParisTech, GEEFT, BP 7355, 34086 Montpellier Cedex 4, France (1)

Available at:
http://www.sciencedirect.com/science/article/pii/S03781
12713005070


21 Abstract. Trees are one of the main components of forest ecosystems; they modify resource 22 levels (light, nutrients, water) that affect understory vegetation composition and diversity.

23 Tree species diversity is used as a biodiversity indicator in various European and French

24 monitoring schemes for sustainable forest management. Moreover, tree species basal area has 25 been found to better indicate floristic biodiversity than tree species richness or diversity.

26 Herein we empirically check this finding by analyzing data from mountain spruce-fir forests

27 in France with Bayesian statistical models. We insist on the magnitude of the relationship and

28 its variation in geographical and ecological space.Our results indicate that both tree species

29 abundance (based on cover or basal area) and tree species richness and dominance are good

30 indicators of some parts of understory vascular plant species richness. The effect of

31 dendrometric indicators on floristic biodiversity varied among ecological groups and along

32 ecological gradients such as aspect, soil acidity, region and altitude. As a result, plots with

33 north-facing and south-facing slopes exhibited opposite relationships of species richness with

34 tree species abundance, and so did plots located on acidic and basic sites. We discuss these

35 results in light of other empirical results relating positive interactions between species and

36 abiotic stress. Our study supports evaluating biodiversity indicators to determine when they

37 actually have non-negligible relationships with biodiversity, i.e. for which ecological groups

38 and in which ecological contexts.

39 Keywords. Biodiversity; indicator; monitoring; ecological gradient; vegetation; vascular 40 plants 
Biodiversity conservation is one of the main objectives stated in the international Convention on Biological Diversity and in associated national strategies. Some of these strategies are sectorial, i.e. they aim to improve biodiversity assessment in specific fields of human activity. Forestry is no exception and biodiversity has been included as one of the six criteria for sustainable forest management in Europe (Ministerial Conference on the Protection of Forests in Europe, 2011). A dozen or so biodiversity indicators have been defined, which vary somewhat among countries. By indicator, we mean any measurable correlate to the particular components of biodiversity being studied (Duelli and Obrist, 2003). Though the creation of such indicators can be a significant step towards better monitoring and conservation of our forest resources, their present form is incomplete. They do not explicitly target specific components of forest biodiversity in specific ecological conditions where the indicator/target component relationship has been established as valid. Furthermore, they do not give information about the magnitude and direction of their relationship with biodiversity (Lindenmayer et al., 2000, Duelli and Obrist, 2003, Lindenmayer and Likens, 2011). In other words, we lack information regarding which specific component of forest biodiversity these indicators can effectively help monitor and in which ecological conditions.

Among the many management choices foresters have to make, the nature of the tree species is a most important one. Tree species identity, abundance and diversity can determine levels of resources available to understory vegetation and influence their spatial variation (Barbier et al., 2008), and can thus shape understory diversity and abundance (Barbier et al., 2009a). This may explain why tree species richness and dominance are used as biodiversity indicators in Europe and France (Ministerial Conference on the Protection of Forests in Europe, 2011, Ministère de l'Agriculture et de la Pêche, 2011). Herein, we define "dominance" as the relative abundance - in terms of cover or basal area - of the most abundant species. Yet, as with many indicators, tree species richness and dominance are not necessarily indicative of all components of biodiversity. Furthermore, these indicators might show influences on biodiversity that work in unexpected directions. Also, other stand-level indicators related to tree species might be better indicators than richness or dominance for some components of floristic biodiversity (Barbier et al., 2009a). Finally, as mentioned by Glenn-Lewin (1977), these indicators might correlate with some components of biodiversity that is in fact due to responses to site type variations - and not to forest management choices. Indeed, when controlling for site type in some lowland French forests, Barbier et al. (2009a) 
found that indicators related to tree species richness and dominance had either negligible effects on floristic biodiversity or effects that were too noisy to conclude; in some cases, the direction of the effect was reversed compared to what was expected based on intuition. In contrast, indicators related to tree species abundance modeled variations in biodiversity more accurately and showed stronger, non-negligible effects.

Our present study can be seen as a follow-up to the study by Barbier et al. (2009a) on the empirical comparison through statistical models of various stand-level indicators of understory biodiversity related to tree species abundance, composition and diversity. Our work is therefore included in the field of empirical studies, which are a vital part to ecology as well as to any other science (e.g. Rigler 1982, Weiner 1995). We chose to work with vascular plants for several reasons: first, because extensive data were available; second, because vascular plants are a relatively diversified group and one that has an important functional role in forest ecosystems; third, because vascular plants are a well-known taxonomic group, that allow to define a priori ecologically more homogenous groups of species. Indeed, our response variable was the species richness of certain ecological groups of vascular plants.

Our first objective was to verify in mountain spruce-fir forests the results Barbier et al. (2009a) found for deciduous lowland forests: i.e. that indicators based on tree species abundance (quantified by crown cover or basal area) would be better indicators of understory biodiversity than richness or dominance.

Our second objective was to study the variation of the relationship between dendrometric indicators and biodiversity along various ecological gradients.Our approach is based on a comparison of the results of Barbier et al. (2009a) with those of Barbier (2007): although the qualitative results in Barbier (2007) were similar to those of Barbier et al. (2009a), the magnitude of the relationships was lower. This discrepancy could have resulted from the inherent instability of the relationship according to the ecological context. Indeed, the 2009 study was carried out in a constant site type in one region with a rather limited variation in soil $\mathrm{pH}$, whereas in 2007 , there were no such controls. If relationships vary with ecological context or region, this could explain the lower magnitude of the effects Barbier found in 2007. We therefore had a second prediction in this study that the relationship between dendrometric indicators and biodiversity would depend on the position along various ecological gradients. This prediction was inspired firstly by general principles (e.g. Biggs et al., 2009) that point in this direction: most ecological relationships are not likely to be general across all ecological conditions but instead should depend on the ecological context. Secondly, it has been shown that relations among vegetation strata or plant species vary along different ecological 
gradients (Callaway et al., 2002, Michalet et al., 2002). Thirdly, the indicators that we study

110 herein are what Austin and Smith (1989) called "indirect gradients", where the variable (such 111 as basal area, for example) affects the plants through other variables which have a direct 112 physiological effect on them. In the case of basal area (and other measures of tree abundance) 113 there is some prior knowledge that it influences both the level of transmitted light (Brown and 114 Parker, 1994, Sonohat et al. 2004) and the proportion of precipitation that reaches the ground 115 (Figure 1 in Barbier et al. 2009b). Barbier et al. (2008) also reviewed knowledge on the 116 impact of dominant tree species on different ecological mechanisms important for plants. 117 These results show that dendrometric indicators are at most indirect gradients for floristic 118 diversity. It is logical expect that the effect of dendrometric indicators on biodiversity should 119 vary with the position along various ecological gradients, since (i) the relationship between 120 direct gradients and floristic diversity can vary in shape - linear, Gaussian, asymmetric, 121 sigmoidal...; (ii) floristic diversity is likely to have limiting factors that depend on the 122 ecological context and (iii) dendrometric indicators influence several of these mechanisms 123 simultaneously. However, the relationship between tree species abundance and floristic 124 biodiversity along ecological gradients is very much related to the stress-gradient hypothesis (e.g. Bertness and Callaway, 1994, Callaway et al., 2002; but see Maestre et al., 2009) which states that positive interactions between species (or between the abundance of one species and the biodiversity of one ecological group) should increase with ecological stress. It should be recognized that ecological stress is not a precise concept (Maestre et al., 2009), but is generally interpreted to refer to ecological conditions in which the productivity of a species is limited by the abiotic environment. The stress-gradient hypothesis not only predicts that relationships between indicators and biodiversity will vary along ecological gradients, but might determine in which direction the relationships occur.

As in Barbier et al. (2009a), we also placed special emphasis on the magnitude of the relationship between floristic biodiversity and biodiversity indicators. However, we changed several parameters: we studied mountain forests rather than lowland forests; we included much more ecological variation in the data and modeled it explicitly in the statistical models; and we increased the number of plots.

To sum up, our objectives were to document how the current list of biodiversity indicators related to forest management can be improved by specifying for which ecological groups and in which ecological contexts these indicators have a non-negligible positive or 
negative statistical relationship with biodiversity - one that cannot be directly attributed to site type variation

\section{Material and methods}

\subsection{Study sites}

The study sites were located in the Alps and Jura great ecological regions (GRECOs; cf. Figure 1), as defined by the NFI. We used the compiled data from the NFI plots, from 2006 to 2010. The GRECOs in France, which are determined according to topography, climate and the geological features of the terrain, each contain several sylvo-ecoregions (SER), which are defined in NFI documentation as the largest geographical zones inside which the factors determining forest production or forest habitat distribution vary in a homogeneous fashion with precise values, resulting in an original combination of these factors, i.e. different from adjacent SERs (Cavaignac, 2009).

For the study we regrouped the SERs of our study area according to an external-internal geographic location of SERs inside the Alps GRECO, with three SERs located in internal Alps (H22:Northern internal Alps, H41:Southern mid-Alps, H42:Southern internal Alps), two in external Alps (H21:Northern external Alps, H30: Southern external Alps) and one in prenorthern Alps (H10: pre-Northern Alps), while Jura was left untouched and contains two SERs (E10: First plateau of Jura, E20:second plateau and Haut-Jura). These four groups defined the variable called Region.

We focused on tree stands dominated by Norway spruce and silver fir (Picea abies and Abies alba). This choice was made because our study was included in a broader project to test biodiversity indicators for inclusion in the tree growth simulation tool CAPSIS (DufourKowalski et al., 2012) for spruce/fir stands. For the selected plots, following Vallet et al. (2011), stands were considered to be pure stands of either species when the basal area of one species (either spruce or fir) was greater than $80 \%$ of the total basal area of the plot. Stands were considered to be mixed when the basal area of both species combined was greater than $80 \%$ of the total basal area of the plot and each of them had a greater basal area than all the other species combined (excluding spruce and fir).

After this initial selection, we removed plots according to two specific criteria.

\section{We first removed winter relevés (when data was collected during December, January or} February) and plots where the operator indicated frozen or snow-covered soil to avoid floristic inventories performed under non-adequate weather conditions. A total of 32 plots were thus removed from the dataset. 
We then removed the NFI "simplified plots", which are plots that are not fully-sized, generally because of a forest edge, road, or other element which reduces the size of the plot. Simplified plots could not be used in the study because there is no indication as to how the simplification was performed, and this prevented further calculations. Plots with reduced sizes were removed, based on the values of tree weight (cf. below), which changes when the plot is downsized. We ended up with a total of 475 plots.

\subsection{Data collection}

\subsubsection{Dendrometric data}

Dendrometric data were taken from NFI relevés. They are summarized in Table SM1 (in the Supplementary Material). The definitions of the variables presented in Table SM1 are listed below. $\mathrm{C}$ is the total tree crown cover on the plot and is the sum of all individual tree covers on the plot, each cover being defined as the ratio of the total surface area of the tree crown's vertical projection to the total plot surface area (0.2 ha). C.spruce, C.fir, C.othersp are the tree crown covers for (respectively) Norway spruce, silver fir and other species. They are calculated from the same cover data, taking tree species into account. Cover was visually estimated by NFI observers.

$\mathrm{G}$ is the total basal area on the plot. It is calculated with diameter at breast height (dbh) and a weighting coefficient, provided by the NFI. Tree censusing is typically done by counting all the trees in a given dbh - actually circumference - interval in three circular subplots centered on the plot centre: a 6m-radius subplot for small trees (from 23.5 to $70.5 \mathrm{~cm}$ in circumference), 9m-radius subplot for medium trees (from 70.5 to $117.5 \mathrm{~cm}$ in circumference) and 15m-radius subplot for big trees (more than $117.5 \mathrm{~cm}$ in circumference). Floristic counts were done at a $15 \mathrm{~m}$-radius subplot. For each tree a weight was thus calculated according to the prospection area corresponding to its dbh class. A change in weight could occur if the plot size is reduced (for example, if a nearby forest path or any other obstacle precludes establishing a fully-sized plot in the field), but also if there are too many trees of the same species inside the same diameter class. G.spruce, G.fir, G.othersp are the basal areas for (respectively) Norway spruce, silver fir and other species. They are calculated from the same data, taking tree species into account. G.BT, G.VBT, G.MT, G.ST are the basal areas for (respectively) large trees (trees with dbh between 42.5 and $67.5 \mathrm{~cm}$ ), very large trees (dbh

207 bigger than $67.5 \mathrm{~cm}$ ), medium trees (dbh between 17.5 and $42.5 \mathrm{~cm}$ ), and small trees (dbh 208 smaller than $17.5 \mathrm{~cm})$. 
rs is tree species richness based on basal area counts.

210 Dominance.C is the tree cover of the most abundant tree species divided by the total tree

211 cover on the plot and Dominance.G is the basal area percentage of the most abundant tree 212 species.

213 Aspect is the magnetic azimuth of the plot's largest slope, measured with an accuracy of

$214 \pm 5$ degrees, and only in non-complex topographical situations, as defined by the NFI protocol.

215 Elevation is the elevation reported by the NFI for the plot (in $\mathrm{m}$ ). Reaction is the estimation of

216 soil $\mathrm{pH}$ derived from the mean of the Ellenberg indicator values for the plants on the plot. The

217 mean function we used was weighted by the abundance of each plant on the plot, based on

218 abundance-dominance with the Braun-Blanquet method as recorded by the NFI floristic

219 relevé and then transformed into cover as in Barbier et al. (2009a). It follows the same order

220 as pH: a low reaction means that the plant is adapted to acidic soils, and a higher value

221 indicates adaptation to basic soils (Ellenberg et al., 1992).

\subsubsection{Floristic data}

The NFI relevés contain information relative to understory species identification and abundance on each plot. Species identification data were coupled with autecological data from Philippe Julve's work on French vegetation and flora (http://philippe.julve.pagespersoorange.fr/). When faced with duplicates inside the database (for example different ecotypes of the same species), the one most fitted to our study was retained. The data regarding species abundance was also used but will not be presented in this paper, as work is still in progress.

Our analysis focused on the species richness of ecological groups rather than on

231 floristic diversity as a whole, based on the considerations in e.g. Barbier et al. (2009a) and

232 Gosselin (2012). Each ecological classification first separated woody and non-woody species.

233 It secondly separated species based on Ellenberg values (light and temperature; Ellenberg et

234 al., 1992) and forest succession association (mature forest species, peri-forest species and 235 non-forest species; as in Barbier et al. 2009a). The number of species in the intersection of 236 these two types of groups (based on life form, then on an ecological classification) gave the 237 species richness of the ecological groups. The use of successional status was motivated by the wide variety of studies that have chosen to work with this classification (Kwiatkowska, 1994;

239 Kwiatkowska et al. 1997; Spyreas and Matthews, 2006; Barbier et al. 2009a), while light and temperature requirements were chosen because they could be important factors to take into 
consideration in order to explain the variations in biodiversity in response to dendrometric 242 indicators.

The Ellenberg values estimated by Julve were based on the ecological requirements of

244 German flora, and extrapolated to France. For example, in the original classification from 1 to

2459 , plants range from extreme shade tolerance to extreme heliophilous behavior. After

246 regrouping the values, values 1 to 3 grouped the shade-tolerant species, 4 to 6 the intermediate

247 species, and 7 to 9 the heliophilous ones. The temperature scale follows the same pattern,

248 from cold-adapted to warm-adapted species. The statistical summary for the species richness

249 of these ecological groups can be found in Table SM2.

\subsubsection{Climatic data}

The meteorological data, obtained from MeteoFrance, included maximum, minimum and mean temperatures for each month and the whole year, as well as mean precipitation for each month and the whole year, for the 2005-2010 period. They were extracted based on the approximate position of the plot given by the NFI, which corresponds to the coordinates of the node to which the plot is linked - the plot is at a maximum of $640 \mathrm{~m}$ from the node. The data required two corrections: a correction based on topography and exposure, and another one based on elevation. As in Michalet et al. (2002), the results from Douguédroit and de Saintignon (1970) were applied to a correction of the decrease in temperature with elevation, with the lapse rates taking into account exposure and topographical situation. The lapse rates, i.e. the rate at which temperature linearly decreases with increasing elevation, were calculated for minimum and maximum temperatures in January and July for valley bottoms and southfacing slopes. By taking means between these extreme situations, we determined the rate to use for each situation in order to obtain our temperature data. In addition to these climatic data, global solar radiation (solrad), soil water capacity (SWC) and potential evapotranspiration (ETP) were calculated as explained in the Supplementary Material. The values of these climatic variables are summarized in Table SM1. Tmin is the temperature for January and potential evapotranspiration, precipitation (PPT) and solar radiation were summed over the growing season, from May to September.

\subsection{Data analysis}

\subsubsection{Statistical models}

The premise of the study was a reflection on the general shape of the statistical models used to relate biodiversity to dendrometric indicators. Our first challenge was to include an 
ecological aspect in the statistical model used to estimate the relationship between biodiversity and ecological variables - excluding dendrometric indicators. By explicitly modeling the site type variation within the statistical biodiversity model, the models may separate the effect of abiotic variables from the effect of the dendrometric indicator on biodiversity. In order to achieve this goal, we chose the abiotic variables according to Austin and Van Nielb (2011): light above the canopy, temperature, reaction, precipitation and topography were included in the model. We did not include $\mathrm{CO}_{2}$ levels, disturbance or biota variables, because $\mathrm{CO}_{2}$ was assumed to be constant for the time span and spatial scale considered in the study, and both biota and disturbance are modeled through the dendrometric indicators.

The dendrometric indicators selected were mostly inspired from Barbier et al. (2009a), with the general goal of comparing tree species richness and dominance indicators with indicators based on tree abundance (cf. Table 1). We added two points to this general objective: whenever possible, we compared models based on cover data to similar models based on basal area data (see below); and we added models which included the basal area of different diameter classes. The latter addition was due to the inclusion of this work in a larger project on tree stand simulators developed to test silvicultural scenarios which are mainly based on diameter classes. Finally, we also added the interactions between the dendrometric models and certain ecological gradients (see below).

The effect of both ecological variables and indicators on the species richness of the different ecological groups was modeled through Bayesian models similar to Generalized Additive Models (GAMs; Harrell, 2001). Since we were analyzing count data, the models we used were mostly equivalent to Poisson GAMs, except that the Poisson distribution was replaced by a more flexible distribution in the Bernoulli/Double Polya mixture-PoissonNegative Binomial family - which allows for both under- and over-dispersion relative to the Poisson distribution (Gosselin, 2011a; Gosselin, Unpublished). This meant that, conditional on all the covariates, the variance of the model could be smaller or larger than the mean. The link function was the classical logarithm link function for Poisson GAMs.

The ecological variables introduced into the model were: soil $\mathrm{pH}$ as indicated by the Ellenberg values of the understory species (denoted as reaction), mean annual temperature $(T)$, growing season precipitation (PPT), solar radiation (solrad), topography, aspect and slope. Temperature, reaction, precipitation and radiation were input into the model through an automatic restricted cubic spline transformation involving four knots, thus requiring the estimation of three parameters for each variable (Harrell, 2001). This transformation is 
classical for species distribution models; it allows the function to model a possible non-linear relationship between the transformed predictor and the explanatory variable. Topography was taken into account through a variable denoted as topo0 with a 1 value for flat positions and 0 otherwise (see Fig. SM1). This allowed us to model the difference between flat topographies and the other topographies. Finally, aspect was taken into account through a cosine function multiplied by a variable related to slope such that the variable was equal to zero for zero slope (no aspect effect) and equal to 1 for slopes of $45^{\circ}$ and steeper. All these variables were put into the model as a linear combination of the logarithm of the mean, The effect of the indicators we wanted to test (see Table 1) was added to this linear combination either alone or in interaction with another ecological variable (see Table 2). The formula for the logarithm of the mean, using a R-like syntax, was therefore: $\operatorname{rcs}($ scale $($ reaction $), 4)+\operatorname{rcs}($ scale $(P P T), 4)+\operatorname{rcs}(\operatorname{scale}(T), 4)+\operatorname{rcs}($ scale $($ solrad $), 4)+\ldots$ $\ldots+$ topo $0+I(\sin (\mathrm{pmin}($ slope,$\pi / 4)) * \cos ($ aspect $))+"$ Indicator model"

where "rcs" is the R function for the restricted cubic spline transformation involving four knots (Harrell, 2001), "I" is the identity link, "pmin" is the parallel minimum function (giving the minimum value after comparing the elements of one or more vectors or matrices), "sin" and "cos" are respectively the sine and cosine trigonometric functions. Another parameter - related to the index of dispersion of the model - was also estimated as a constant. The priors probability distributions of the fixed effects - i.e. the probability distributions of the corresponding statistical parameters, before the data is taken into account - were mostly weakly informative, often with a normal distribution of mean 0 and a standard deviation of 2 as prior distributions.

330 This model structure was used throughout with variations only in the "Indicator model", 331 which we now come to. The indicator models were either the models specified in Table 1 or 332 the models in Table 1 plus the interaction of this model with one of the ecological variables in 333 Table 2. As the ecological variable itself was often already present in the model, and to 334 compare models on similar grounds, the simple ecological effect itself was not included in the 335 model. The ecological variables investigated either corresponded to geographic regions as 336 advocated by Biggs et al. (2009), ecological variables related to ecological stress (especially 337 water stress) as studied by Michalet et al. (2002) and Callaway et al. (2002) (precipitation, 338 temperature, exposure,...) and soil $\mathrm{pH}$, inspired from Tyler (1989). The aspect model included a slope component because aspect effect was modulated by the value of the slope. 
The simple models were then tested on the successional ecological groups successively to determine for each group which indicators gave the best results. For each ecological group, we then compared the best indicator model, first without interaction and then in interaction with the ecological variables in Table 2. We selected four ecological variables that involved the best models for further analyses (see Results section).

The Bayesian models were fitted through an adaptation of the algorithm proposed by Vrugt et al. (2009) based on four trajectories, and a thinning parameter of 50. The convergence of the models was checked with the Rubin and Gelman Rhat quantity, below 1.1 (Gelman et al., 2004). After convergence was reached, we asked each model to estimate 2,000 values of the parameters.

To compare our models with each other, we used a modified version of the DIC Deviance Information Criterion (Spiegelhalter et al., 2002) -, as discussed by Celeux et al. (2006), which consists in calculating the reference Deviance not at the mean of the parameters but at an estimate of its mode - which here corresponded to the set of parameters leading to the highest posterior probability. Indeed, the classical version of the DIC yielded incoherent, unstable results with negative values for the number of parameters, a problem that the modebased DIC did not have.

\subsubsection{Analysis of model results}

For each model, the direction and magnitude of the effects of the indicator parameters were analyzed with the same methods as in Barbier et al. (2009a). For each indicator parameter we studied the effect on the mean fitted value for species richness of an increase in the ecological parameter of around one standard deviation. We chose the following increases for the different parameters: $10 \mathrm{~m}^{2} \cdot \mathrm{ha}^{-1}$ for most basal area parameters $\left(5 \mathrm{~m}^{2} \cdot \mathrm{ha}^{-1}\right.$ for G.othersp and G.ST, respectively basal area of species other than fir or spruce and basal area of stems less than $17.5 \mathrm{~cm}$ in $\mathrm{dbh}$ ), $15 \%$ for all tree crown cover parameters, except $7.5 \%$ for C.othersp, 1.5 genera for tree species richness and 0.2 for tree species dominance. For each parameter, we reported the mean value of the log of the multiplier of the mean corresponding to such a variation, its $95 \%$ confidence interval, and the probability of the significance test that the parameter was null. Levels of statistical significance for parameters were symbolized as follows: $*^{*}=\mathrm{p}<0.01$ and $*=\mathrm{p}<0.05$. Inspired from Dixon and Pechmann (2005), we also

371 did an analysis based on equivalence and inequivalence tests to detect negligible effects:

372 based on Bayesian parameter estimations as in Camp et al. (2008), the aim of this analysis 
was to identify (i) when the parameter has a high probability of being in an interval, called the negligible interval, that is a priori considered to represent negligible effects, (ii) when the parameter had a high probability of being below this interval and (iii) when the parameter had a high probability of being above it. Two negligible intervals were distinguished: one for weak negligibility and one for strong negligibility. We denoted by $0<b_{1}<b_{2}$ the levels associated to the two negligible intervals. We used the symbol 0 to describes cases where $\mathrm{P}(-$ $\left.\mathrm{b}_{2}<\log (\beta)<\mathrm{b}_{2}\right) \geq 0.95$ and 00 for the more stringent: $\mathrm{P}\left(-\mathrm{b}_{1}<\log (\beta)<\mathrm{b}_{1}\right) \geq 0.95$. Similarly, we denoted by "-" cases where $\mathrm{P}\left(\log (\beta)<-\mathrm{b}_{1}\right) \geq 0.95$ and "--" cases where $\mathrm{P}\left(\log (\beta)<-\mathrm{b}_{2}\right) \geq$ 0.95 . These cases correspond to non-negligible negative and strongly non-negligible negative effects, respectively. We had similar notations - "+" and "++" - for the positive side. We chose $\mathrm{b}_{1}=0.1$ and $\mathrm{b}_{2}=0.2$ for species richness data, corresponding respectively to a multiplication of species richness by $\exp (0.1) \approx 1.11$ and $\exp (0.2) \approx 1.22$ at the upper side of the negligible interval.

We addressed our two main predictions by using a mixture of analyses based on models comparison and the analysis of the magnitude of the effects of the models. Our first prediction was that dendrometric models involving only tree abundance would be more robust than those with either tree species richness or stand dominance. Our analyses relied on two forms of evidence, both for dendrometric models without interaction with other ecological variables and those with interaction either with aspect, altitude, reaction or region, which were the most active variables among those tested (listed in Table 3; cf. Results section): (i) model comparisons: for each category of dendrometric model (between Total Abundance, Abundance by tree species, Abundance by diameter class, Tree species richness and Tree dominance and abundance), either based on crown cover or on basal area, we recorded the number of times the category of model was the best, the second best, and so on. We also recorded the mean difference in DIC with the best model, over the 16 ecological groups studied. A model that had less difference in DIC and a higher rank was interpreted as being a better model than the others;

(ii) magnitude and significance of the effects: for each dendrometric parameter among the floristic ecological groups, we recorded the number of times it was negative and significant to the $1 \%$ level, positive and significant to the $1 \%$ level, judged negligible, negative non negligible, positive non negligible or without enough information relative to negligibility of the effect. These parameters were grouped in the same categories as in (i) above, except that 
we also identified parameters for pure abundance (i.e. total abundance based either on crown cover or basal area).

Our second prediction stated that dendrometric indicators would have relationships with biodiversity that would depend on the ecological context. To tackle this prediction, having selected the best four ecological variables (reaction, altitude, exposure and region; cf. below), we compared the difference in DIC between the best model with interaction and the best model without interaction. When the DIC value for the model with interaction was lower by at least 5 DIC units from the model without an interaction, we interpreted this as an indication of an interaction with the ecological gradient.

We then analyzed the magnitude of the effect of the dendrometric parameters on floristic diversity in different ecological contexts to interpret the direction of this interaction. To do this, for each dendrometric parameter we listed the ecological groups and ecological contexts in which the relationship between the dendrometric parameter and the species richness of the ecological group was judged negative non-negligible or positive non-negligible (cf. above). For each dendrometric parameter, we also identified the ecological groups that were still significantly negative non-negligible or positive non-negligible after the multi-comparison correction proposed by Rice (1989). The estimators were taken at flat positions and at slope = $50 \%$ and aspects East or West, South and North aspect for aspect/slope models, and as the mean $+1 *$ sd and mean- $1 *$ sd for elevation and reaction gradients.

To more collectively analyze the dependence of the indicator-biodiversity relationship on the ecological context, we calculated the mean and standard deviation across ecological groups of the difference at both ends of the ecological gradient in the mean effect of a typical variation of the indicator on the log of the mean species richness. The differences taken were the difference between South and North aspect at slope $=50 \%$ for aspect/slope models and as the mean $+2 *$ sd and mean $-2 *$ sd for elevation and reaction gradients.

Finally, we checked the statistical quality of our models by using the new goodness of fit pvalues proposed by Gosselin (2011b), called the sampled posterior p-values. We applied these p-values on different aspects of normalized residuals (as described in Gosselin, 2011b): their skewness, their kurtosis - to diagnose the probability distribution used -, their correlation with the estimated mean - to diagnose general linearity problems - and with the covariates incorporated in the models (precipitation, solar radiation, reaction, temperature...). To detect potentially non-monotonous correlations between variables, we used the Hoeffding's D statistic provided in the Hmisc R package (Harrell, 2001). We applied this method to the best model of each ecological group. We also checked the multi-collinearity of our variables of 
interest by calculating the variance inflation factor (VIF) of all the dendrometric variables we were interested in as a function of all the other variables in the model (Zuur et al., 2010).

\section{Results}

\subsection{Choice of model}

To determine which ecological gradients to include in interactions with our dendrometric models, the simple models were first tested on the successional ecological groups to determine which indicators gave the best results (Table SM.7). These indicators were then run with the ecological variables in interaction as indicated in Table 2. Table SM.8 gives the results of this first comparison. The best models were: the "region:G.D" model for mature forest and peri-forest herbaceous species, the "region:G.sp" model for non-forest herbaceous species, the "region:RS" model for mature forest woody species and the "reaction:G.sp" model for peri-forest woody species. Altogether, the aspect, elevation, reaction and region variables performed best (see Table SM.8).

Furthermore, the goodness-of-fit checks of the best models of each group revealed some significant departures from the probabilistic hypotheses in the models for more than half of the ecological groups (9 over 16; Table SM.9). These departures involved the probability distribution for species richness (4 cases) - indicating a problem in the probability distribution used for these ecological groups -, the log link function (4 cases) or the relationships with some ecological variables ( 8 cases in total) - indicating that more complex relationships might be warranted for these groups.

Finally, regarding multicolinearity, some dendrometric variables in the simple models had mildly problematic levels of VIF between 2 and 3 for the cover of spruce and fir (C.fir and C.spruce) and for the total cover and dominance based on cover ( $\mathrm{C}$ and Dominance.C) in the Cover dominance model. For the first two, the problem was not strongly exacerbated in the models with interaction. The other dendrometric variables had non problematic VIF values below 2 (Zuur et al., 2010).

3.2 Prediction 1: dendrometric models based on abundance (i.e. basal area and tree cover) are better than those based on dominance or tree species richness

Dendrometric models formulated on abundance data were better models overall than those based on tree species richness (Table 3 and Tables SM3 to SM6). Indeed, the abundancebased models (i.e. G.sp and C.sp in Ab.SP and G.D) were the best for one third of the 
473 biodiversity ecological groups on average whereas the species richness model (RS) was the

474 best for at most one sixth of the ecological groups. Furthermore, for the RS model, the mean

475 difference in DIC from the DIC of the best model ranged from $40 \%$ to more than $150 \%$ more

476 than for models based on abundance. Dom models (including Dom.C and Dom.G) involving

477 both tree species dominance and total tree species abundance were intermediate but rarely

478 provided the best model.

479 However, analysis of the significance and magnitude of the effects of the parameters in these

480 different models tempered the above results. Indeed, overall, the parameters in the tree species

481 richness models had the highest chance of involving a non-negligible relationship, whatever

482 the context (Table 4). Moreover, this result was not due to abundance parameters involving

483 more cases where there was not enough information to conclude. Rather the reverse was true.

484 The result was tempered for statistically significant results: the best variables were those

485 based on absolute abundance in the tree stand. Furthermore, when only herbaceous floristic

486 biodiversity was analyzed, leaving aside woody ecological groups, tree species richness

487 models were slightly surpassed by abundance models, by tree species or by diameter class for

488 the mean of significant results, although they still involved the most non-negligible

489 relationships on average (cf. Table 5). Also, for the five dendrometric variables that involved

490 the greatest number of significant results or the most number of non-negligible results,

491 dendrometric variables involving abundance data (total abundance, spruce abundance or

492 abundance of trees less than $17.5 \mathrm{~cm} \mathrm{dbh}$ ) appeared among the first (cf. Tables $4 \& 5$ ). Tree

493 species richness was still a good dendrometric variable. Overall, tree species richness had

494 more positive than negative significant or non-negligible effects for woody floristic ecological

495 groups, but the reverse was true when the analysis was restricted to herbaceous ecological

496 groups (compare Tables $4 \& 5$ ). Variables related to tree abundance had mostly negative

497 effects on floristic biodiversity (see Table 4).

498

4993.3 Prediction $2:$ : dendrometric indicators have relationships with biodiversity that depend

500 on the ecological context:

501 An interaction between dendrometric variables and ecological context was detected for most

502 of the ecological groups (cf. Table 6). Only two ecological groups (peri-forest herbaceous

503 species and intermediate light-demanding woody species) had DIC differences of more than -

5045 between the best interaction model and the best simple model, while five ecological groups

505 (non-forest herbaceous species, heliophilous herbaceous species, cold-temperature herbaceous 
506 species, mid-temperature woody species and high-temperature woody species) had a DIC 507 difference of less than -20 .

508 Regarding the ecological groups and contexts in which each dendrometric variable was a non509 negligible indicator of biodiversity (cf. Table 7), most ecological groups were indicated in 510 specific ecological contexts, as hypothesized. Only in a few cases did dendrometric indicators 511 indicate a non-negligible variation across all the plots analyzed ( 2 for C.spruce, 1 for G.ST, 1 512 for G.spruce, 2 for rs and 1 for Dominance.G). Indicators related to tree abundance mostly 513 negatively impacted non-forest, high-light or low-temperature herbaceous species, mostly in 514 northern aspects, at lower elevations and in more acidic conditions. We noticed a counter 515 relationship of a positive non-negligible effect of some tree abundance attributes on south 516 facing slopes for low-light herbaceous species. We also noticed a positive effect of the basal 517 area of tree species other than spruce and fir on four ecological groups in the Internal Alps 518 (results not shown). Spruce cover and basal area as well as the basal area of trees less than $519 \quad 17.5 \mathrm{~cm}$ in dbh (G.ST) were the most involved in relationships with biodiversity.

520 The picture was somewhat different for tree species richness indicators: they mostly had 521 positive non-negligible effects on the species richness of herbaceous and woody forest species as well as low-temperature woody species. Tree species richness had noticeable negative effects on some herbaceous species groups, mostly for groups and in ecological conditions for

524 which there was also a negative impact of tree abundance indicators.

525 In addition, stand dominance based on basal area had a negative effect on low-temperature 526 woody species in many ecological contexts and on forest herbaceous species in two ecological 527 contexts.

Finally, by analyzing the variation across ecological groups of their response to each dendrometric ecological indicator along ecological gradients (cf. Table 8), we detected

531 unilateral variations in biodiversity in response to total cover, fir cover and spruce cover along 532 the reaction and aspect gradients. Slightly less strong results were detected for equivalent 533 basal area data as well as for the basal area of trees between 17.5 and $42.5 \mathrm{dbh}$. A slight 534 reverse trend was found for tree species richness based on cover for the aspect gradient and 535 for tree species dominance for the reaction gradient. Another, "variational" response, where 536 there was no strong central trend and considerable variation among ecological groups, was 537 detected for most cases along the elevation gradient as well as for some other cases along the 538 aspect and reaction gradients, especially for tree species richness. This means that while some 
539 species groups had a response to the indicator that increased rather strongly along the

540 gradient, other species groups decreased strongly.

\section{Discussion}

4.1 Identifying the best dendrometric indicators of floristic variables

544 Our first prediction was that models involving tree abundance could account for variations in

545 floristic species richness better than models involving either tree species richness or

546 dominance. At the statistical model level, our prediction was met. This was not completely the

547 case at the individual predictor level, where variables in abundance models were on average

548 associated with fewer non-negligible effects than tree species richness variables. Finally, the

549 two best abundance variables, basal area of the smallest diameter class and spruce cover,

550 competed well with tree species richness in terms of non-negligible or significant results. Our

551 results are therefore less clear-cut than Barbier et al. (2009a) where the analyses based on

552 model comparisons and magnitude of the effects clearly converged. Nonetheless, our results

553 support considering models based on tree abundance as indicators of floristic biodiversity, as

554 suggested by many previous studies (Moir, 1966, McCune and Antos, 1981, Specht and

555 Morgan, 1981, Pitkanen, 2000, Brosofske et al., 2001, Ohlemüller et al., 2004, Laughlin et al.,

556 2005, Lindh, 2005, references in Barbier 2009 and Vockenhuber et al., 2011). Our results also

557 suggest, however, that tree species richness may be a good univariate indicator of biodiversity

558 for some ecological groups, in accordance with previous results in the literature (Auclair and

559 Goff, 1971, Hicks, 1980, Ingerpuu et al., 2003, Vockenhuber et al., 2011 and references in

560 Barbier et al., 2008).

561 We are unsure at this stage why spruce abundance and small diameter tree abundance are

562 better indicators than the abundance of other tree species or diameter classes. Spruce

563 abundance performance in our study is all the more surprising that Mitchell and Kirby (1989),

564 when summarizing the literature, listed spruce and fir as having similar effects on floristic

565 species composition. This is not what we have found, although we did not analyze species

566 composition directly nor did we analyze the effect of spruce stand dominance, but rather the

567 effect of spruce abundance. It should be noted that spruce abundance and small diameter tree

568 abundance indicated - mostly negatively - partly different ecological groups (peri-forest

569 herbaceous species for small diameter tree abundance, heliophilous herbaceous species for

570 spruce abundance). 
571 Multivariate models such as ours should be further studied to determine whether they are

572 better than univariate models of abundance or than univariate models involving the relative 573 abundance of some tree species, a commonly used variable in forest ecology (Ewald, 2000,

574 Mölder et al., 2008). We promote using absolute abundance rather than relative abundance 575 because it is more directly linked with ecological mechanisms, even though it has yet to be 576 confirmed as a better indicator. In any case, we advise testing abundance-based as well as 577 diversity-based dendrometric quantities as biodiversity indicators.

4.2 The relationship between dendrometric indicators and floristic biodiversity depends on the ecological group and the ecological context

581 Our second prediction was rather general; it stated that the relationship between dendrometric 582 indicators and floristic biodiversity should depend on the ecological context. This prediction 583 was inspired firstly by general considerations as well as more specific results that point in this 584 direction (cf. Introduction section): most ecological relationships are not likely to be general 585 across all ecological conditions but instead should depend on the ecological context. Our 586 results partially confirmed our second prediction: the best models always included an interaction of dendrometric indicators with an ecological gradient (cf. Table 6). The relationships between individual indicators and the biodiversity of specific ecological groups were more often non-negligible in certain specific locations (Northern slopes and Jura for abundance models; Jura, Northern Alps, Internal Alps for RS). However, overall, though the

591 frequency of non-negligible cases was less frequent in simple models (2.9\% of all groups,

$5923.7 \%$ for herbaceous groups only) than in models analyzed in specific ecological contexts

593 (3.7\% of all groups, $5.4 \%$ for herbaceous groups only), the differences between these 594 frequencies were non-significant. This result means that even if we demonstrated the 595 importance of ecological context in the dendrometric indicator - biodiversity relationship, this 596 importance is somewhat relative.

$598 \quad 4.3$ Analysis of biodiversity relationships with indicators along gradients

599 In addition to studying the relationship between dendrometric indicators and floristic species 600 richness in specific ecological conditions, we also used a rather novel type of analysis to study 601 how these relationships vary among species groups along ecological gradients (cf. Table 8). 602 This analysis allowed us to characterize cases where the indicator/biodiversity relationship 
603 was relatively stable across groups along the ecological gradient, but only in relative terms,

604 i.e. in terms of the differences between the coefficients of the indicators between groups. In 605 other words, there was a parallel shift of the relationship across groups along the gradient 606 (bold cases in Table 8). This is similar to a null model in which different ecological groups 607 respond differentially to an indicator, but with a difference in coefficients that remains 608 constant along the gradient. This was the case for indicators based on spruce and fir crown 609 cover measurements along the aspect and reaction gradients. These results could be translated 610 in ecological terms as a global shift from negative interactions between canopy abundance 611 and floristic biodiversity to more positive interactions from one side of the gradient to the 612 other.

613 In other cases, not only was the relative difference between estimators constant along the 614 gradient, but the estimators themselves were relatively constant in absolute terms. This 615 indicates that the relationship was stable between the indicator and biodiversity along the 616 gradient. For example, this was the case for the basal area of very large trees or the crown 617 cover of trees other than spruce and fir along the elevation gradient.

618 A third interesting case appeared where there was no central tendency in the variation in the 619 indicator/biodiversity relationship among ecological groups along the gradient but instead a strong variance among ecological groups along the gradient (italic cases in Table 8). This occurred for most of the indicators along the elevation gradient as well as for some indicators along the aspect and reaction gradients. In this case, the indicator could very well be related to biodiversity in some regions of the ecological gradient, but the biodiversity/indicator relationship was unstable across ecological groups in relative terms along the ecological 625 gradient.

4.4 Two contrasted gradients for the relationship between tree abundance indicators and herbaceous groups: aspect and soil reaction gradients Following other authors, Austin and Van Niela (2011) made the point that species distribution models should incorporate topographic variables to better predict the future distribution of

631 species in response to climate change. Our results on floristic biodiversity in forests are along 632 the same lines but we go a step further: our results indicate that not only should we take into 633 account topographic information, we should also take into account tree abundance and the 634 interaction between tree abundance and topographic variables. Our results indicate that denser tree cover would decrease some floristic stand-level diversity in northern aspects while it 
636 would promote other components of floristic diversity in southern aspects. This can be

637 interpreted in terms of the stress/facilitation hypothesis which states that positive interactions 638 between species are more likely in more ecologically stressful conditions (Callaway et al., 639 2002, Callaway, 1997, Michalet et al., 2002). Indeed, if we had used the Index of Moisture 640 Availability (IMA) as did Laughlin et al. (2005, based on Batek et al., 1999), our aspect 641 gradient would have been transformed into a water stress gradient since the IMA predicts 642 greater water stress on steep south-facing slopes. However, other mechanisms may become 643 limiting at certain points along the aspect gradient (e.g. light on northern aspects when tree 644 abundance is high and light levels are reduced). Therefore, we should not too hastily explain 645 the effect of such an indirect ecological gradient, in our case aspect, by a unique more direct 646 ecological gradient (see also Soliveres et al., 2011).

647 Michalet et al. (2002) observed that floristic species composition differed in fir and spruce 648 stands in the French Alps on southern aspects but not on northern aspects. This seems to be a 649 result qualitatively similar to ours in that it indicates an interaction of tree species effect on 650 biodiversity along the aspect gradient. However, in our study, the species richness response of 651 the ecological groups to fir abundance did not strongly differ from their response to spruce 652 abundance along the aspect gradient. Therefore, our results are not completely in agreement 653 with those of Michalet et al. (2002). One difference between Michalet et al. (2002)'s study 654 and ours is that we investigated the impact of tree species abundance, and not tree species 655 dominance in the stand. Also, while Michalet et al. studied species composition, we analyzed 656 the species richness of ecological groups, which reflects presence-absence species 657 composition only if the species inside each ecological group have homogeneous ecological 658 behaviors.

Similar observations were made on the soil reaction gradient - indicative of soil $\mathrm{pH}$.

660 Here too, there was an opposite effect at each end of the gradient. The effects of tree

661 abundance on the species richness of many ecological groups were mostly negative in more 662 acidic conditions, while they were more positive in less acidic conditions (cf.Table 8 \& Tables 663 SM.35 to SM.40). Ecologically interpreting this case in terms of stress is more difficult 664 because soil $\mathrm{pH}$ should indicate stress at both ends of the gradient, where two different 665 resources are involved (water and nutrients; Maestre et al., 2009). This should result in 666 positive effects of tree abundance at both ends of the gradient, unless the stress-gradient 667 hypothesis is refined as indicated by Maestre et al. (2009). Still our results appear to be in the 668 opposite direction to those of Tyler (1989), who documented a more negative effect of tree 669 crown cover on floristic diversity in less acidic conditions than in more acidic conditions. 
670 Similarly, we did not confirm the stress-facilitation hypothesis along the altitudinal gradient as 671 did Callaway et al. (2002) (cf. Table 8 \& Tables SM.28 to SM.33). Our results therefore 672 indicate that the "classic" stress-facilitation hypothesis appears on some gradients (here the 673 aspect gradient) but not on others (elevation and reaction) for the species richness of 674 ecological groups. This finding must still be verified through the analysis of the ecological 675 group abundance and species abundance.

6774.5 Implications for forest management and biodiversity indicators

678 Of course, as for many observational ecological results, our results should be checked with 679 other observational data, other methods of analysis and with experimental data before they 680 can be applied with confidence in management. For example, we did not integrate all the 681 interesting ecological groups nor did we analyze abundance data. Our study was also limited 682 because we considered only one broad taxonomic group (understory vascular plant), which is 683 not necessarily indicative of all forest biodiversity. Work should be pursued in these directions 684 and our results should therefore not be unduly generalized.

685 Should our results be confirmed, we could say that variables such as spruce abundance, small 686 diameter tree basal area and tree species richness have a non-negligible relationship with the 687 species richness of relatively numerous floristic ecological groups. The relationships we 688 found were mostly negative for spruce abundance and small diameter tree abundance but can 689 be both negative and positive for tree species richness. Secondly, some of the abundance 690 parameters had interactions with some of the ecological gradients that were in the same 691 direction for the different ecological groups. This resulted, for example, in effects that 692 globally changed from negative to positive from northern aspects to southern aspects 693 (respectively, from acidic conditions to less acidic conditions) for the abundance of spruce 694 trees (respectively, spruce basal area and cover, fir cover, and basal area of big trees). This 695 means that if floristic biodiversity is the objective, managers should apply opposite guidelines 696 in these contrasted ecological conditions.

698 Our results support our initial prediction (cf. also Barbier et al., 2008, Barbier et al., 2009a) 699 which states that biodiversity indicators only reflect a part of the biodiversity in specific 700 ecological conditions. Our work therefore promotes evaluating biodiversity indicators to 701 specify in which ecological contexts and for which component of biodiversity the indicator 702 has a non-negligible relationship and whether the relationship is positive or negative. 
Acknowledgements. This work was supported by the French Ministry of Agriculture through grant $n^{\circ}$ E 23/2010 and FP7-KBBE project "ARANGE" (n² 289437). We thank Benoît Courbaud, Thomas Cordonnier and Valentine Lafond for comments on dendrometric indicators for silvicultural models. Patrick Vallet and Maude Toigo provided useful help on the NFI database. We thank Vincent Boulanger (ONF) and two anonymous reviewers for their help in improving the manuscript. We thank Vicki Moore for correcting the English.

\section{References:}

Auclair, A. N. and F. G. Goff, 1971. Diversity relations of upland forests in the western Great Lakes area. The American Naturalist, 105(946), 499-528.

Austin, M. P. and K. P. Van Niel, 2011a. Impact of landscape predictors on climate change modelling of species distributions: A case study with Eucalyptus fastigata in southern New South Wales, Australia. Journal of Biogeography, 38(1), 9-19.

Austin, M. P. and K. P. Van Niel, 2011b. Improving species distribution models for climate change studies: Variable selection and scale. Journal of Biogeography, 38(1), 1-8.

Austin, M. P. and T. M. Smith, 1989. A new model for the continuum concept. Vegetatio, 83(1-2), 35-47.

Barbier, S., 2007. Influence de la diversité, de la composition et de l'abondance des essences forestières sur la diversité floristique des forêts tempérées. Ph.D thesis Thesis, Université d'Orléans, Orléans.

Barbier, S., F. Gosselin and P. Balandier, 2008. Influence of tree species on understory vegetation diversity and mechanisms involved - a critical review for temperate and boreal forests. Forest Ecology and Management, 254(1), 1-15.

Barbier, S., R. Chevalier, P. Loussot, L. Bergès and F. Gosselin, 2009a. Improving biodiversity indicators of sustainable forest management: tree genus abundance rather than tree genus richness and dominance for understory vegetation in French lowland oak hornbeam forests. Forest Ecology and Management, 258( ), S176-S186.

Barbier, S., P. Balandier and F. Gosselin, 2009b. Influence of several tree traits on rainfall partitioning in temperate and boreal forests: a review. Annals of Forest Science, 66(602). 
734 Batek, M. J., A. J. Rebertus, W. A. Schroeder, T. L. Haithcoat, E. Compas et al., 1999.

735 Reconstruction of early nineteenth-century vegetation and fire regimes in the Missouri 736 Ozarks. Journal of Biogeography, 26(2), 397-412.

737 Bertness, M. D. and R. Callaway, 1994. Positive interactions in communities. Trends in 738 Ecology and Evolution, 9(5), 187-191.

739 Biggs, R., S. R. Carpenter and W. A. Brock, 2009. Spurious certainty: How ignoring 740 measurement error and environmental heterogeneity may contribute to environmental 741 controversies. BioScience, 59(1), 65-76.

742 Brosofske, K. D., J. Chen and T. R. Crow, 2001. Understory vegetation and site factors: 743 implications for a managed Wisconsin landscape. Forest Ecology and Management, 146(1-3), $744 \quad 75-87$.

745 Brown, M. J. and G. G. Parker, 1994. Canopy light transmittance in a chronosequence of 746 mixed-species deciduous forests. Canadian Journal of Forest Research, 24(8), 1694-1703.

747 Callaway, R. M., 1997. Positive interactions in plant communities and the individualistic748 continuum concept. Oecologia, 112(2), 143-149.

749 Callaway, R. M., R. W. Brooker, P. Choler, Z. Kikvidze, C. J. Lortie et al., 2002. Positive 750 interactions among alpine plants increase with stress. Nature, 417(6891), 844-848.

751 Camp, R. J., N. E. Seavy, P. M. Gorresen and M. H. Reynolds, 2008. A statistical test to show 752 negligible trend: Comment. Ecology, 89(5), 1469-1472.

753 Cavaignac, S., 2009. Les sylvoécorégions (SER) de France métropolitaine, Etude de 754 définition, French National Forest Inventory, Nogent sur Vernisson.

755 Celeux, G., F. Forbesy, C. P. Robertz and D. M. Titteringtonx, 2006. Deviance information 756 criteria for missing data models. Bayesian Analysis, 1(4), 651-674.

757 Dixon, P. M. and J. H. K. Pechmann, 2005. A statistical test to show negligible trend. 758 Ecology, 86(7), 1751-1756. 
Douguédroit, A. and M. F. de Saintignon, 1970. Méthode d'étude de la décroissance des

760 températures en montagne de latitude moyenne: Exemple des alpes françaises du sud. Revue 761 de géographie alpine, 58, 453-472.

762 Duelli, Peter and Martin K. Obrist, 2003. Biodiversity indicators: the choice of values and measures. Agriculture, Ecosystems \& Environment, 2063, 1-12.

764 Dufour-Kowalski, S., B. Courbaud, P. Dreyfus, C. Meredieu and F. De Coligny, 2012.

765 Capsis: An open software framework and community for forest growth modelling. Annals of 766 Forest Science, 69(2), 221-233.

767 Ellenberg, H., H. E. Weber, R. Düll, V. Wirth, W. Werner et al., 1992, Zeigerwerte von 768 Pflanzen in Mitteleuropa, vol. 18 (). Verlag Goltze, Göttingen.

769 Ewald, J., 2000. The partial influence of Norway spruce stands on understorey vegetation in 770 montane forests of the Bavarian Alps. Mountain Research and Development, 20(4), 364-371.

771 Gelman, A., J. B. Carlin, H. S. Stern and D. B. Rubin, 2004, Bayesian Data Analysis (). 772 Chapman \& Hall, Boca Raton.

773 Glenn-Lewin, D. C., 1977. Species diversity in North American temperate forests. Vegetatio, $774 \quad 33,153-162$.

775 Gosselin, F., 2011a. Propositions pour améliorer l'équipement biométrique du détective 776 écologique. Application à la modélisation de la relation entregestion forestière et biodiversité. 777 HDR Thesis, Université Pierre et Marie Curie, Paris.

778 Gosselin, F., 2011b. A New Calibrated Bayesian Internal Goodness-of-Fit Method: Sampled 779 Posterior p-values as Simple and General p-values that Allow Double Use of the Data. Plos 780 One, 6(3), e14770.

781 Gosselin, F., 2012. Improving Approaches to the Analysis of Functional and Taxonomic 782 Biotic Homogenization: beyond Mean Specialization. Journal of Ecology, 100(6), 1289-1295.

783 Harrell, F. E., 2001, Regression Modeling Strategies, With Applications to Linear Models, 784 Logistic Regression, and Survival Analysis. Springer, New York, USA. 
785 Hicks, D. J., 1980. Intrastand distribution patterns of southern Appalachian forest herbaceous 786 species. American Midland Naturalist, 104(2), 209-223.

787 Ingerpuu, N., K. Vellak, J. Liira and M. Partel, 2003. Relationships between species richness 788 patterns in deciduous forests at the north Estonian limestone escarpment. Journal of 789 Vegetation Science, 14(5), 773-780.

790 Kwiatkowska, A. J., 1994. Changes in the species richness, spatial pattern and species 791 frequency associated with the decline of oak forest. Vegetatio, 112(2), 171-180.

792 Kwiatkowska, A. J., K. Spalik, E. Michalak, A. Palinska and D. Panufnik, 1997. Influence of 793 the size and density of Carpinus betulus on the spatial distribution and rate of deletion of 794 forest-floor species in thermophilous oak forest. Plant Ecology, 129(1), 1-10.

795 Laughlin, D. C., J. D. Bakker and P. Z. Fule, 2005. Understorey plant community structure in 796 lower montane and subalpine forests, Grand Canyon National Park, USA. Journal of 797 Biogeography, 32(12), 2083-2102.

798 Lindenmayer, D. B., C. R. Margules and D. B. Botkin, 2000. Indicators of biodiversity for 799 ecologically sustainable forest management. Conservation Biology, 14(4), 941-950.

800 Lindenmayer, D. B. and G. E. Likens, 2011. Direct Measurement Versus Surrogate Indicator 801 Species for Evaluating Environmental Change and Biodiversity Loss. Ecosystems, 14(1), 4780259.

803 Lindh, B. C., 2005. Effects of conifer basal area on understory herb presence, abundance, and 804 flowering in a second-growth Douglas-fir forest. Canadian Journal of Forest Research, 35(4), 805 938-948.

806 Maestre, F. T., R. M. Callaway, F. Valladares and C. J. Lortie, 2009. Refining the stress807 gradient hypothesis for competition and facilitation in plant communities. Journal of Ecology, 808 97(2), 199-205 DI 10.1111/j.136.

809 McCune, B. and J. A. Antos, 1981. Diversity relationships of forest layers in the Swan Valley, 810 Montana. Bulletin of the Torrey Botanical Club, 108(3), 354-361. 
811 Michalet, R., Rolland, C., Joud, D., Gafta, D. and Callaway, R. M., 2002. Associations

812 between canopy and understory species increase along a rainshadow gradient in the Alps:

813 Habitat heterogeneity or facilitation? Plant Ecology, 165(2), 145-160.

814 Ministère de l'Agriculture et de la Pêche, 2011. Les indicateurs de gestion durable des forêts 815 françaises métropolotaines - Edition 2010, MAP, Paris.

816 Ministerial Conference on the Protection of Forests in Europe, 2011. State of Europe's forests

8172011 - Status and trends in Sustainable Forest Management in Europe.

818 Mitchell, P. L. and K. J. Kirby, 1989, Ecological effects of forestry practices in long819 established woodland and their implications for nature conservation (). Oxford Forestry 820 Institute, Oxford.

821 Moir, W. H., 1966. Influence of ponderosa pine on herbaceous vegetation. Ecology, 47(6), $822 \quad 1045-1048$.

823 Mölder, A., M. Bernhardt-Römermann and W. Schmidt, 2008. Herb-layer diversity in 824 deciduous forests: Raised by tree richness or beaten by beech? Forest Ecology and 825 Management, 256(3), 272-281.

826 Morneau, F., C. Duprez and J. C. Hervé, 2008. Mixed-species forests in metropolitan France 827 Chraracterization based on national forest inventory findings. Revue Forestiere Francaise, 828 60(2), 107-120.

829 Ohlemüller, R., P. Bannister, K. J.M. Dickinson, S. Walker, B. J. Anderson et al., 2004.

830 Correlates of vascular plant species richness in fragmented indigenous forests: Assessing the 831 role of local and regional factors. Community Ecology, 5(1), 45-54.

832 Pitkanen, S., 2000. Effect of tree stand and site variables on alpha diversity of ground 833 vegetation in the forests of Northern Karelia. Journal of Environmental Management, 58(4), 834 289-295.

835 Rice, W. R., 1989. Analyzing tables of statistical tests. Evolution, 43, 223-225.

836 Rigler, F. H., 1982. Recognition of the possible: an advantage of empiricism in ecology. 837 Canadian Journal of Fisheries and Aquatic Sciences, 39(9), 1323-1331. 
838 Soliveres, S., D. J. Eldridge, F. T. Maestre, M. A. Bowker, M. Tighe et al., 2011.

839 Microhabitat amelioration and reduced competition among understorey plants as drivers of

840 facilitation across environmental gradients: Towards a unifying framework. Perspectives in

841 Plant Ecology, Evolution and Systematics, 13(4), 247-258.

842 Sonohat, G., P. Balandier and F. Ruchaud, 2004. Predicting solar radiation transmittance in 843 the understory of even-aged coniferous stands in temperate forests. Annals of Forest Science, 844 61, 629-641.

845 Specht, R. L. and D. G. Morgan, 1981. The balance between the foliage projective covers of 846 overstorey and understorey strata in Australian vegetation. Australian Journal of Ecology, 6, $847 \quad 193-202$.

848 Spiegelhalter, D.J., N.G. Best, J. B. Carlin and A. van der Linde, 2002. Bayesian measures of 849 model complexity and fit (with Discussion). Journal of the Royal Statistical Society, Series B, 850 64(4), 583-616.

851 Spyreas, G. and J. W. Matthews, 2006. Floristic conservation value, nested understory floras, 852 and the development of second-growth forest. Ecological Applications, 16(4), 1351-1366.

853 Tyler, G., 1989. Interacting effects of soil acidity and canopy cover on the species 854 composition of field-layer vegetation in oak/hornbeam forests. Forest Ecology and 855 Management, 28(2), 101-114.

856 Vockenhuber, E. A., C. Scherber, C. Langenbruch, M. Meißner, D. Seidel et al., 2011. Tree 857 diversity and environmental context predict herb species richness and cover in Germany's 858 largest connected deciduous forest. Perspectives in Plant Ecology, Evolution and Systematics, 859 13(2), 111-119.

860 Vrugt, J. A., C. J.F. Ter Braak, C. G.H. Diks, B. A. Robinson, J. M. Hyman et al., 2009. 861 Accelerating Markov chain Monte Carlo simulation by differential evolution with self862 adaptive randomized subspace sampling. International Journal of Nonlinear Sciences and 863 Numerical Simulation, 10(3), 273-290.

864 Weiner, J., 1995. On the pratcice of ecology. Journal of Ecology, 83, 153-158.

865 Zuur, Alain F., Elena N. Ieno and Chris S. Elphick, 2010. A protocol for data exploration to 866 avoid common statistical problems. Methods in Ecology and Evolution, 1(1), 3-14. 
867 Table 1. Dendrometric variables used in the dendrometric indicator models without

868 interaction with ecological gradients

\begin{tabular}{lll}
\hline Model & Variable content of the model in R syntax & Model symbol \\
\hline Total cover & $\sim \mathrm{C}$ & $\mathrm{C}$ \\
Total basal area & $\sim \mathrm{G}$ & $\mathrm{G}$ \\
Cover per tree species & $\sim$ C.spruce + C.fir + C.othersp & C.sp \\
Basal area per tree species & $\sim$ G.spruce + G.fir + G.othersp & G.sp \\
Basal area per diameter class & $\sim$ G.BT + G.VBT + G.MT + G.ST & G.D \\
Tree species richness & $\sim$ rs & RS \\
Cover dominance & $\sim$ Dominance.C + C & Dom.C \\
Basal area dominance & $\sim$ Dominance.G + G & Dom.G \\
Null model & $\sim 1$ & \\
\hline
\end{tabular}

869

870

871

872 
873 Table 2. Shape of the dendrometric indicator models with interactions with ecological

874 gradients. The "indicator model" is one of the models in Table 1.

Ecological gradient involved in the interaction

Variable content of the model in R syntax

Region (categorical variable with four levels; cf. text)

"Indicator model"+ "Indicator model":Region

"Indicator model"+ ...

Aspect (including slope)

...”Indicator model":((1-topo0)*toposimple*slope* $2 / \pi+\ldots$

Reaction

...(1-topo 0$) *$ toposimple*slope $* 2 / \pi * \cos ($ aspect $))$

Elevation

"Indicator model"+ "Indicator model":(Reaction)

ETP

ح'Indicator model"+ "Indicator model":(Elevation)

SWC

ح'Indicator model"+ "Indicator model":(ETP)

Tmin

ح"Indicator model"+ "Indicator model":(SWC)

ح'Indicator model"+ "Indicator model":(Tmin)

PPT

"Indicator model"+ "Indicator model":(PPT)

ETP stands for evapotranspiration, SWC for soil water content and ppt for precipitations, and toposimple equals one is there 
878 Table 3. Number of times - over the 16 ecological groups - that each group of models was 879 ranked first, second, third or fourth compared to the other groups in terms of DIC comparison 880 for the no-interaction models. For the two groups that included two models (Ab.SP and Dom), 881 the best of the two models was considered. The last line gives the mean DIC difference 882 between the best model in the category and the best model in total: the largest the difference, 883 the furthest the model from the best model in total.

\begin{tabular}{lllll}
\hline Rank & Ab.SP & G.D & Dom & RS \\
\hline First & 6 & 6 & 2 & 2 \\
Second & 3 & 3 & 7 & 3 \\
Third & 3 & 4 & 7 & 2 \\
Fourth & 4 & 3 & 0 & 9
\end{tabular}

884 Ab.SP stands for both C.sp and G.sp models, and Dom stands for both Dom.C and Dom.G models. 
Table 4. (A). Mean over the dendrometric variables in the abundance or RS or dominance models of the number of cases in each category of effect (classified either according to the negligibility of the effect or its $1 \%$ significance: cf. section 2.3.2 "Analysis of model results") over the 16 ecological groups and over the 15 cases analyzed in Tables SM 10 to 40. (B) Same information for the 5 dendrometric variables with the most significant relationships (corresponding to the sum of the last two lines). (C) Same information for the 5 dendrometric 892 variables with the most non-negligible relationships (corresponding to the sum of lines 2 and 893 3).

894

\begin{tabular}{llllll} 
A & \multicolumn{7}{l}{} \\
\hline Level of significance & Ab.Tot & Ab.SP & G.D & RS & Dom \\
\hline negligible & 235,5 & 198,33 & 199 & 164,5 & 211 \\
negative non-neg & 8 & 7,67 & 5,25 & 6,5 & 5,5 \\
positive non-neg & 0,5 & 1,17 & 0 & 13,5 & 0 \\
no info negligible & 0,5 & 33,83 & 36,25 & 56 & 23,5 \\
positive signicant & 18,5 & 16,5 & 3,75 & 60,5 & 2 \\
negative signicant & 64,5 & 43,33 & 47 & 12,5 & 58,5 \\
\hline
\end{tabular}

\begin{tabular}{|c|c|c|c|c|c|}
\hline Level of significance & G.spruce & G.ST & C.spruce & G & C \\
\hline negligible & 195 & 146 & 209 & 237 & 234 \\
\hline negative non-neg & 20 & 13 & 20 & 7 & 9 \\
\hline positive non-neg & 1 & 0 & 1 & 0 & 1 \\
\hline no info negligible & 26 & 81 & 12 & 0 & 1 \\
\hline positive signicant & 20 & 1 & 25 & 8 & 29 \\
\hline negative signicant & 88 & 97 & 71 & 76 & 53 \\
\hline
\end{tabular}

C

\begin{tabular}{llllll}
\hline Level of significance & RS & G.spruce & C.spruce & G.ST & Dominance.G \\
\hline negligible & 147 & 195 & 209 & 146 & 119 \\
negative non-neg & 13 & 20 & 20 & 13 & 6 \\
positive non-neg & 16 & 1 & 1 & 0 & 0 \\
no info negligible & 65 & 26 & 12 & 81 & 19 \\
positive signicant & 51 & 20 & 25 & 1 & 1 \\
negative signicant & 23 & 88 & 71 & 97 & 31 \\
\hline
\end{tabular}

896

897

898

899 
902

903

904

905

906

907

908

909

910

Table 5. (A). Mean over the dendrometric variables in the abundance or RS or dominance models of the number of cases in each category of effect (classified either according to the negligibility of the effect or its $1 \%$ significance: cf. section 2.3.2 "Analysis of model results") over the 9 herbaceous ecological groups and over the 15 cases analyzed in Tables SM 7 to 37. (B) Same information for the 5 dendrometric variables with the most significant relationships (corresponding to the sum of the last two lines). (C) Same information for the 5 dendrometric variables with the most non-negligible relationships (corresponding to the sum of lines 2 and $3)$.

\begin{tabular}{llllll} 
A & \multicolumn{1}{l}{} & & \\
\hline Level of significance & Ab.Tot & Ab.SP & G.D & RS & Dom \\
\hline negligible & 130,5 & 106,83 & 107 & 89,5 & 123 \\
negative non-neg & 8 & 7,33 & 5 & 6,5 & 2 \\
positive non-neg & 0,5 & 0,67 & 0 & 5,5 & 0 \\
no info negligible & 0,5 & 21,17 & 23,5 & 33,5 & 10 \\
positive signicant & 17 & 10,67 & 3,25 & 24,5 & 2 \\
negative signicant & 47,5 & 28 & 36,25 & 12,5 & 29
\end{tabular}

\begin{tabular}{llllll} 
B & \multicolumn{7}{l}{ Level of significance } & G.ST & C.spruce & C & G.spruce & G \\
\hline negligible & 70 & 108 & 129 & 96 & 132 \\
negative non-neg & 12 & 20 & 9 & 19 & 7 \\
positive non-neg & 0 & 1 & 1 & 1 & 0 \\
no info negligible & 53 & 8 & 1 & 21 & 0 \\
positive signicant & 0 & 24 & 26 & 20 & 8 \\
negative signicant & 79 & 54 & 47 & 49 & 48 \\
\hline
\end{tabular}

\begin{tabular}{|c|c|c|c|c|c|}
\hline Level of significance & C.spruce & G.spruce & RS & G.ST & C \\
\hline negligible & 108 & 96 & 75 & 70 & 129 \\
\hline negative non-neg & 20 & 19 & 13 & 12 & 9 \\
\hline positive non-neg & 1 & 1 & 5 & 0 & 1 \\
\hline no info negligible & 8 & 21 & 42 & 53 & 1 \\
\hline positive signicant & 24 & 20 & 11 & 0 & 26 \\
\hline negative signicant & 54 & 49 & 23 & 79 & 47 \\
\hline
\end{tabular}


913 Table 6. DIC difference between the best interaction model and the best model without 914 interaction, for each ecological group, together with the identity of the best indicator model 915 and ecological gradient involved in the best interaction model.

\begin{tabular}{llll}
\hline Ecological group & $\Delta \mathrm{DIC}$ & Type of model & Type of gradient \\
\hline h.MF & -9.36 & G.D & reaction \\
h.PF & -1.5 & G.D & aspect \\
H.NF & -38.64 & C & altitude \\
w.MF & -7.83 & C & reaction \\
w.PF & -10.91 & Dom.G & altitude \\
h.HL & -29.07 & C & altitude \\
h.IL & -4.36 & G.D & aspect \\
h.LL & -6.31 & C & reaction \\
w.HL & -16 & C.sp & reaction \\
w.IL & -8.02 & Dom.G & altitude \\
h.HT & -14.98 & Dom.G & region \\
h.IT & -8.25 & G.D & aspect \\
h.LT & -40.58 & C.sp & altitude \\
w.HT & -7.2 & G.sp & reaction \\
w.IT & -29.14 & Dom.G & altitude \\
w.LT & -28.93 & Dom.G & altitude
\end{tabular}

916 h. and w. respectively stand for herbaceous and woody species; MF, NF and PF for mature forest, non-forest and peri-forest 917 species; HL, IL and LL for high-light, intermediate-light and low-light species; HT, IT and LT for high-temperature,

918 intermediate-temperature and low-temperature species. The names of the gradients refer to the models defined in Table 2. 
Table 7. List of the cases where each dendrometric variable in the models in Table 1 had a non-negligible effect on the species richness of an ecological group in general or in a given evnvironmental context (with respect to reaction, aspect or elevation). We here distinguish negative and positive non negligible cases for the Cover of trees (C) and the tree species richness (RS) and indicate the mean estimate and 95\% credibility interval for the natural logarithm of the multiplicative effect on mean species richness of a non-negligible increase in the dendrometric parameter. The lines in bold indicate the ecological groups and ecological contexts that were still significantly negative non-negligible or positive nonnegligible after the multi-comparison correction proposed by Rice (1989), at the level of each dendrometric parameter. See Tables SM.10 and SM.11 to SM.41 for further results.

\begin{tabular}{|c|c|c|c|c|}
\hline Variable in the model & Negative non-negligible effects & & Positive non-negligible effects & \\
\hline \multirow{17}{*}{ C } & h. HL at slope $=0.5 \& \mathrm{E} / \mathrm{W}$ aspect & & h.LL at slope $=0.5 \& S$ aspect & \\
\hline & & $-0.131[-0.168 ;-0.0943]$ & & $0.177[0.0991 ; 0.256]$ \\
\hline & h.NF at slope $=0.5 \& \mathrm{~N}$ aspect & & & \\
\hline & & $-0.154[-0.205 ;-0.102]$ & & \\
\hline & h. HL at slope $=0.5 \& \mathrm{~N}$ aspect & & & \\
\hline & & $-0.202[-0.263 ;-0.142]$ & & \\
\hline & h. $\mathrm{HL}$ at Reaction $=5$ & & & \\
\hline & & $-0.144[-0.179 ;-0.109]$ & & \\
\hline & h.NF at Reaction $=4.5$ & & & \\
\hline & & $-0.16[-0.209 ;-0.111]$ & & \\
\hline & h. HL at Reaction=4.5 & & & \\
\hline & & $-0.201[-0.255 ;-0.147]$ & & \\
\hline & h.LT at Reaction $=4.5$ & & & \\
\hline & & $-0.147[-0.199 ;-0.097]$ & & \\
\hline & h. $\mathrm{HL}$ at Elevation $=770 \mathrm{~m}$ & & & \\
\hline & & $-0.172[-0.215 ;-0.132]$ & & \\
\hline & h.HL & & W.LT & \\
\hline \multirow[t]{9}{*}{ rs } & & $-0.208[-0.307 ;-0.112]$ & & $0.213[0.0773 ; 0.348]$ \\
\hline & h. HL at slope $=0.5 \& \mathrm{E} / \mathrm{W}$ aspect & & h.MF on flat terrain & \\
\hline & & $-0.237[-0.347 ;-0.129]$ & & $0.182[0.0988 ; 0.263]$ \\
\hline & h.NF at slope $=0.5 \& \mathrm{~N}$ aspect & & w.MF at slope $=0.5 \& \mathrm{E} / \mathrm{W}$ aspe & \\
\hline & & $-0.292[-0.464 ;-0.0978]$ & & $0.149[0.0993 ; 0.207]$ \\
\hline & h. $\mathrm{HL}$ at slope $=0.5 \& \mathrm{~N}$ aspect & & w.LT at slope $=0.5 \& \mathrm{~N}$ aspect & \\
\hline & & $-0.413[-0.612 ;-0.214]$ & & $0.403[0.118 ; 0.668]$ \\
\hline & h. $\mathrm{HL}$ at Reaction $=5$ & & h.MF at Reaction $=5.5$ & \\
\hline & & $-0.222[-0.32 ;-0.12]$ & & $0.211[0.122 ; 0.307]$ \\
\hline
\end{tabular}


h. $\mathrm{HL}$ at Reaction $=4.5$

h. $\mathrm{HL}$ at Elevation $=1120 \mathrm{~m}$

h.NF at Elevation $=770 \mathrm{~m}$

\section{h. $\mathrm{HL}$ at Elevation $=770 \mathrm{~m}$}

h.LT at Elevation $=770 \mathrm{~m}$
w.MF at Reaction $=4.5$

$-0.253[-0.402 ;-0.104]$

w. LT at Reaction $=4.5$

$-0.229[-0.325 ;-0.13]$

$-0.317[-0.425 ;-0.22]$

$w . L T$ at Elevation $=1460 \mathrm{~m}$

$-0.379[-0.511 ;-0.255]$

h.MF at Elevation $=770 \mathrm{~m}$

w.MF at Elevation $=770 \mathrm{~m}$
$0.173[0.0972 ; 0.253]$

$0.308[0.116 ; 0.513$

$0.405[0.256 ; 0.561]$

0.179 [0.109; 0.249$]$

0.168 [0.117; 0.22$]$

$-0.249[-0.356 ;-0.132]$

h. and w. respectively stand for herbaceous and woody species; MF, NF and PF for mature forest, non-forest and peri-forest species; HL, IL and LL for high-light, intermediate-light and low-light species; HT and LT for high-temperature and low-temperature species. We here considered the simple models as well as the Aspect, Altitude and Reaction models defined in Table 2. We recall that a positive non-negligible effect means that there is a probability of 0.95 that the effect of adding a "non-negligible" variation of a given dendrometric parameter results in at least an

$\exp (0.1)$ multiplication of the mean of species richness. We chose the following "non-negligible" increases for the different parameters: $15 \%$ for tree crown cover parameters, and 1.5 genera for tree species richness. 
935 Table 8. Mean (Standard deviation) across 16 ecological groups of the difference of the mean 936 log response of species richness to a substantive variation in the indicator between both ends 937 of each gradient. We put in italics the cases where the standard deviation is above $0.1-$

938 indicating a strong variation in this difference among groups - and in bold those for which the 939 absolute value of the mean is above 0.1 - indicating a strong mean variation that is shared by

940 the groups. Substantial variations of indicators are the same as those mentioned in Table 7.

\begin{tabular}{llll}
\hline Variable & N-S aspect & +2 reaction & $+1380 \mathrm{~m}$ elevation \\
\hline C & $0.1(0.05)$ & $\mathbf{0 . 1 9}(\mathbf{0 . 0 8})$ & $0.04(0.13)$ \\
C.fir & $\mathbf{0 . 1 1}(\mathbf{0 . 0 5})$ & $\mathbf{0 . 2 6}(\mathbf{0 . 0 9})$ & $0.04(0.15)$ \\
C.spruce & $\mathbf{0 . 1 7}(\mathbf{0 . 1})$ & $\mathbf{0 . 2 1}(\mathbf{0 . 0 6})$ & $0.05(0.12)$ \\
C.othersp & $-0.03(0.08)$ & $0.05(0.09)$ & $0(0.06)$ \\
G.BT & $0.04(0.06)$ & $\mathbf{0 . 1 4}(\mathbf{0 . 1 3})$ & $0.03(0.13)$ \\
G.VBT & $0.04(0.1)$ & $0.07(0.09)$ & $0.02(0.05)$ \\
G.MT & $0.1(0.08)$ & $\mathbf{0 . 1 2}(\mathbf{0 . 1})$ & $0.05(0.18)$ \\
G.ST & $\mathbf{0 . 1 2 ( 0 . 1 8 )}$ & $0.07(0.1)$ & $-0.03(0.09)$ \\
G.fir & $0.05(0.05)$ & $\mathbf{0 . 1 1}(\mathbf{0 . 0 4})$ & $0.02(0.12)$ \\
G.spruce & $\mathbf{0 . 1 4}(\mathbf{0 . 1 5})$ & $\mathbf{0 . 1 3}(\mathbf{0 . 0 8})$ & $0.04(0.17)$ \\
G.othersp & $-0.04(0.17)$ & $-0.02(0.34)$ & $-0.03(0.17)$ \\
G & $0.06(0.07)$ & $\mathbf{0 . 1 1}(\mathbf{0 . 0 5})$ & $0.02(0.13)$ \\
RS & $0.09(0.18)$ & $0.09(0.25)$ & $\mathbf{0 . 1 2}(0.38)$ \\
Dominance.G & $-0.04(0.07)$ & $-0.1(0.07)$ & $0.01(0.19)$ \\
Dominance.C & $0.02(0.06)$ & $0.09(0.07)$ & $-0.02(0.14)$ \\
\hline
\end{tabular}

941

942

943 